\title{
Assessment of adaptability of recently released salt tolerant rice varieties in coastal regions of South Bangladesh
}

\author{
M. R. Islam ${ }^{1}$, M. R. A. Sarker², N. Sharma², M. A. Rahman², B. C. Y. Collard ${ }^{1}$, G. B. \\ Gregorio $^{1}$ and A. M. Ismail $^{3 *}$
}

${ }^{1}$ Plant Breeding, Genetics and Biotechnology Division, International Rice Research Institute, Philippines; ${ }^{2}$ Plant Breeding Division, Bangladesh Rice Research Institute, Bangladesh; ${ }^{3}$ Crop and Environmental Sciences Division, International Rice Research Institute, Philippines

*Corresponding author; Crop and Environmental Sciences Division, International Rice Research Institute, DAPO Box 7777, Metro Manila, Philippines. Tel.: +63 2580 5600; Fax: +63 2580 5699. E-mail: a.ismail@irri.org_(A. M. Ismail).

\begin{abstract}
Productivity of rice is adversely affected by salinity and water logging stresses in coastal zones, and affected areas are progressively expanding as consequences of climate change and overexploitation of natural resources to meet the needs of increasing populations. Several varieties were developed and commercialized in this region in recent years, including some salt and stagnant flood (SF, medium deep, $25-50 \mathrm{~cm}$ water depth) tolerant varieties. However, suitability of these varieties based on adaptation to local conditions across the region and farmers' preferences have not been sufficiently evaluated. Genotype by environment analysis leads to identification of varieties with stable performance, or suitability to specific regions. Two
\end{abstract}


frequently used statistical analyses are additive main effects and multiplicative interaction (AMMI); and the genotype main effects and genotype $\times$ environment interaction effects (GGE). These models were used in this study to identify stable rice varieties for the wet and dry seasons in South Bangladesh. Experiments were conducted at six sites over four years (2010 - 2013) in coastal Bangladesh, using eight and five varieties for wet and dry season, respectively. The trials were laid in a randomized complete block design (RCBD) with three replications. Genotypic contribution was much higher than the environmental effect on grain yield in the wet season, while the environmental contribution was much higher than genotypic effect during the dry season. SF stress affected yield of wet season rice; but in the dry season, salinity stress had major effect on grain yield. The variety BRRI dhan54 was identified as the most suitable genotype with wider adaptability in the region during the wet season, followed by BRRI dhan 40 and BRRI dhan53, while BRRI dhan47 was the most stable variety followed by BRRI dhan61 and BINA dhan8 for the dry season across all sites. However, when these varieties were evaluated based on farmers' preferences in participatory varietal selection, BRRI dhan53; a short duration variety with medium slender grains was the most preferred, followed by BRRI dhan54 and BRRI dhan40 for wet season, and in the dry season BRRI dhan47 was the most popular variety followed by BRRI dhan61, which agreed with ranking based on yield. Modern varieties were far superior over traditional varieties based on grain yield and farmers' preferences, and should be targeted for large-scale seed production and dissemination.

Key Words: Adaptability; farmers' preferences, genotype x environment analysis, salinity, stagnant floods. 


\section{Introduction}

Growth and productivity of rice in coastal tropical areas are adversely affected by various abiotic stresses, including stagnant (SF, medium-deep, $25-50 \mathrm{~cm}$ for most of the season) and flash floods (complete submergence for 1-2 weeks). Rice is the main crop in these areas, and can thrive in shallow flooded soils, but is more sensitive to salinity and deeper floods (Munns and Tester, 2008; Ismail et al., 2013; Ismail and Mackill, 2014). About 1.0 M hectares of arable land in coastal areas of Bangladesh is affected by salinity (Islam et al., 2008a) and categorized into four classes; $\mathrm{S}_{1}\left(\mathrm{EC}<4 \mathrm{dS} \mathrm{m} \mathrm{m}^{-1}\right), \mathrm{S}_{2}\left(\mathrm{EC}=4-8 \mathrm{dS} \mathrm{m} \mathrm{m}^{-1}\right), \mathrm{S}_{3}\left(\mathrm{EC}=8-15 \mathrm{dS} \mathrm{m}{ }^{-1}\right)$ and $\mathrm{S}_{4}(\mathrm{EC}>15$ $\mathrm{dS} \mathrm{m}{ }^{-1}$ ) (Islam et al., 2013). Among these categories, $S_{1}$ to $S_{3}$ are being used for rice production in the wet season, while brackish water shrimp and salt farming were pursued in $\mathrm{S}_{4}$ areas.

Soil salinity is therefore, considered one of the major constraints for rice production in these coastal areas of Bangladesh. Both soil and water are saline due to inundation of the offshore by tidal water and concentration of salt due to excessive evaporation during the dry season. Coexistence of saline soil, saline surface and groundwater and extreme temperatures (high and low) has made this ecosystem extremely challenging for successful rice production. Moreover, the adverse effects of these constraints are increasing progressively as a consequence of climate change, further limiting rice production and threatening food security (Islam et al., 2008a). Between 2007 and 2008, the high food prices and natural disasters significantly aggravated poverty and exacerbated vulnerability to food insecurity in the whole of Bangladesh. Devastating cyclones and floods further worsen the situation in South Bangladesh. On 25 May 2009, cyclone "AILA" ripped through the southern coast, inflicting heavy damages on properties and assets of over 3.5 million people. This catastrophic incidence was only 18 months after cyclone "SIDR" struck the same coastal zone in 2007. A tidal surge accompanying the storm 
inundated vast tracts of land washing away thousands of homes and damaging standing crops, livestock and fisheries enclosures.

Modern rice varieties have not been widely adopted in these areas and traditional varieties are still being grown by farmers because they can partially withstand floods and salt stresses, but they are low yielding; with long duration and are photoperiod sensitive. Recently, several improved rice varieties were developed conventionally and evaluated through participatory variety selection (PVS) approach, in which farmers could directly be involved in selecting a rice genotype before release as a variety. Furthermore, these varieties have little or no photoperiod sensitivity, and all are short to medium duration, have good grain quality and thus more suited to fitting 2 or 3 crops per year. Moderately salt tolerant $\left(\mathrm{EC}=6-8 \mathrm{dS} \mathrm{m}^{-1}\right)$ rice varieties like BR23, BRRI dhan40 and BRRI dhan41 have limited adaptability in those areas because their seedlings are short, making them more sensitive to SF (Salam et al., 2010). Furthermore, large area in this coastal zone remained fallow during the dry season (November April) due to high soil and water salinity.

Development of stress tolerant, high yielding rice varieties is one of the mandates of the International Rice Research Institute (IRRI) and the national rice research programs in Asia, to ensure sustainable rice production and food security for the vast growing population in countries like Bangladesh. Several varieties were recently developed but have not been disseminated on larger-scale in the region. Identifying the most widely adapted and acceptable among these varieties will help optimize resources and strategies for seed production and distribution to reach most farmers.

Multi-location testing of promising breeding lines along with released abiotic stress tolerant varieties usually reflect strong genotype-by-environment interactions that often 
complicate the interpretation of results (Annicchiarico and Perenzin, 1994). Genotype by environment analysis could lead to the identification of varieties with stable performance that can be grown over wider and variable environments in South Bangladesh. Grain yield is a complex quantitative trait, greatly influenced by environmental variation. Hence, the selection of superior genotypes based on yield per se at a single location in a year will not be effective (Shrestha et al., 2012). Therefore, evaluation for yield stability in several variable environments has become an essential part of breeding programs (Tariku et al., 2013).

Several methods have been proposed to analyze data from multi-location trials or perform genotype $\mathrm{x}$ environment (G x E) analysis. Two frequently used statistical analyses are the additive main effects and multiplicative interaction (AMMI) model and the genotype main effects and genotype $\times$ environment interaction effects (GGE) model (Gauch, 2006). The AMMI model has been extensively applied in the statistical analysis of multi-environment cultivar trials (Kempton, 1984; Crossa, 1990; Gauch and Zobel, 1997). For AMMI, the additive portion is separated from interaction by analysis of variance (ANOVA). Then the principal component analysis (PCA) provides a multiplicative model applied to analyze the interaction effects from the additive ANOVA model. Integrating biplot displays and genotypic stability statistics enables genotypes to be grouped based on similarity of performance across diverse environments (Thillainathan and Femandez, 2001). The GGE biplot model provides a more complete and visual evaluation of all aspects of the data by creating a biplot that simultaneously represents mean performance and stability, and also identifies mega-environments (Ding et al., 2007; Kang, 1993; Yan, 2001; Yan and Kang, 2003; Rad et al., 2013). The GGE biplot can be useful to display the which-won-where pattern of the data that may lead to identifying high-yielding and stable cultivars and discriminating test environments (Yan, 2001; Rad et al., 2013). 
The objectives of this study are therefore, to perform $\mathrm{G} \times \mathrm{E}$ analysis to assess the extent of genotype $\mathrm{x}$ environment interactions (GEI) for grain yield of salt tolerant rice genotypes in different areas (sites) of coastal Bangladesh; to evaluate these genotypes for their yield stability, farmers and consumers preferences and for suitability to cultivate them either in specific or in wide range of environments. The analyses were conducted using AMMI and GGE biplot models using four-year data.

\section{Materials and Methods}

\subsection{Plant material}

A number of salt tolerant rice varieties were developed through conventional breeding and released for both wet and dry seasons in coastal saline areas of south Bangladesh over the recent past (Islam and Gregorio, 2013). Average grain yield and other agronomic characteristics of these varieties were presented in Table 1 (BRRI, 2013). A four-year study (2010 - 2013) was conducted using these varieties, together with the three traditional varieties Sadamota, Morichshail and Kumri, in the wet season.

\section{Table 1}

Agronomic characteristics and grain quality traits of released salt tolerant rice varieties for wet and dry seasons in Bangladesh (BRRI, 2013)

\begin{tabular}{|l|c|c|c|c|c|c|c|c|c|}
\hline Variety & $\begin{array}{c}\text { Genotype } \\
\text { code }\end{array}$ & $\begin{array}{c}\text { Growth } \\
\text { duration }\end{array}$ & $\begin{array}{c}\text { Plant } \\
\text { height } \\
(\mathbf{c m})\end{array}$ & $\begin{array}{c}\text { Grain } \\
\text { shape }\end{array}$ & $\begin{array}{c}\text { Amylose } \\
\text { content } \\
(\%)\end{array}$ & $\begin{array}{c}\text { Salt } \\
\text { tolerance } \\
\text { Score (SES) }^{*}\end{array}$ & $\begin{array}{c}\text { Y i l I d } \\
\text { t ha }^{-1}\end{array}$ & $\begin{array}{c}\text { Release } \\
\text { Year }\end{array}$ \\
\hline Wet season varieties & G1 & 150 & 110 & MS & 27.0 & 5 & 4.0 & 1988 \\
\hline BR23 & G2 & 144 & 120 & MB & 25.7 & 5 & 5.0 & 2003 \\
\hline BRRI dhan40 & G3 & 142 & 122 & MS & 24.1 & 5 & 5.0 & 2003 \\
\hline BRRI dhan41 & G4 & 122 & 105 & LS & 25.9 & 5 & 4.5 & 2010 \\
\hline $\begin{array}{l}\text { BRRI dhan53 (BR5778-156- } \\
\text { 1-3-HR14) }\end{array}$ & & & & & & & & \\
\hline BRRI dhan54 (BR5999-82-3- & G5 & 135 & 115 & LS & 25.7 & 5 & 5.5 & 2010 \\
\hline
\end{tabular}




\begin{tabular}{|l|c|c|c|c|c|c|c|c|}
\hline 2-HR1) & & & & & & & & \\
\hline Kumri & G6 & 166 & 167 & Bold & 27.2 & 7 & 2.4 & Traditional \\
\hline Morichshail & G7 & 169 & 163 & Bold & 27 & 7 & 2.7 & Traditional \\
\hline Sadamota & G8 & 165 & 152 & Bold & 27.5 & 7 & 3.0 & Traditional \\
\hline
\end{tabular}

\section{Dry season varieties}

\begin{tabular}{|l|c|c|c|c|c|c|c|c|}
\hline BRRI dhan28 & G2 & 140 & 111 & LS & 28.4 & 7 & 4.6 & 1994 \\
\hline BRRI dhan47 & G3 & 145 & 102 & Bold & 28.3 & 3 & 6.2 & 2007 \\
\hline $\begin{array}{l}\text { BINA dhan8 (IR66946-3R- } \\
\text { 149-1-1) }\end{array}$ & G1 & 146 & 100 & Bold & 26.6 & 3 & 5.7 & 2010 \\
\hline $\begin{array}{l}\text { BRRI dhan55 (IR73678-6-9- } \\
\text { B) }\end{array}$ & G4 & 145 & 100 & LS & 22.2 & 5 & 5.1 & 2011 \\
\hline BRRI dhan61 (BR7105-4R-2) & G5 & 145 & 96 & MS & 26.4 & 3 & 6.3 & 2013 \\
\hline
\end{tabular}

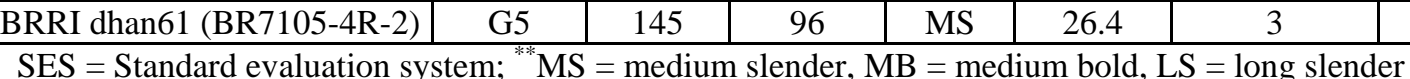

The three traditional varieties are popular among farmers because they are tall, making them more tolerant to stagnant floods, respond better to low fertilizer use but are low yielding ( $2-2.5 \mathrm{t}$ $\mathrm{ha}^{-1}$ ), susceptible to lodging and are strongly photoperiod sensitive with long growth duration (160-170 d). Eight varieties including 5 modern and 3 traditional varieties were used in the wet season and five modern varieties were evaluated during the dry season. The trials were conducted across different salt affected areas in order to assess the adaptability of these varieties to different environments as well as their suitability based on farmers' preferences across the regions.

The elite breeding lines (later released as varieties) BR5778-156-1-3-HR14 (released as BRRI dhan53) and BR5999-82-3-2-HR1 (BRRI dhan54), along with the released varieties BR23, BRRI dhan40 and BRRI dhan41, for the wet season; and IR66946-3R-149-1-1 (BINA dhan8), IR73678-6-9-B (BRRI dhan55) and BR7105-4R-2 (BRRI dhan61) together with the released varieties BRRI dhan28 and BRRI dhan47 for the dry season, were used in the trials. Each set was evaluated during relevant (wet or dry) season in six sub-districts of 5 salt affected coastal districts; Satkhira (Shyamnagar and Kaliganj), Khulna (Batiaghata), Pirojpur (Nazirpur), Feni (Sonagazi) and Noakhali (Noakhali Sadar). 


\subsection{Trial description}

The description of the six sites was shown in Table 2 (BBS, 2013). Thirty and forty day-old seedlings were transplanted during the wet and dry seasons, respectively, using 2-3 seedlings per hill at a spacing of $25 \times 15 \mathrm{~cm}$, with a plot size of $16.2 \mathrm{~m}^{2}$. A randomized complete block design (RCBD) with 3 replicates was used. Fertilizers were applied at 80 (Wet season) and 120 (dry): 60: $40 \mathrm{~kg} \mathrm{~N}: \mathrm{P}: \mathrm{K} \mathrm{ha}^{-1}$. Gypsum and $\mathrm{ZnSO}_{4}$ were applied at $40 \mathrm{~kg} \mathrm{ha}^{-1}$ and $10 \mathrm{~kg} \mathrm{ha}^{-1}$, respectively. $\mathrm{N}$ was applied in three splits at 15, 30 and $45 \mathrm{~d}$ after transplanting (DAT) in the wet season and 15, 35 and 55 DAT in dry season, respectively. The recommended amounts of P, K, gypsum and $\mathrm{ZnSO}_{4}$ were applied during the final land preparation. Other cultural management practices were performed as and when necessary. Data were collected on yield $\left(\mathrm{t} \mathrm{ha}^{-1}\right)$, duration $(\mathrm{d})$ and plant height $(\mathrm{cm})$ and analyzed using GenStat $\left(16^{\text {th }}\right.$ edition 2013 , VSN International) and PBTools (Version 1.4, http://bbi.irri.org/products). The water salinity was monitored every alternate day in the experimental plots and their surroundings using portable electrical conductivity (EC) meter (HANNA, HI 8733) during both wet and dry seasons and ranges of water salinity were summarized in Table 3.

\section{Table 2}

Description of experimental locations based on historical data from Bangladesh Bureau of Statistics (BBS, 2013).

\begin{tabular}{|l|l|l|l|l|l|l|}
\hline \multirow{2}{*}{ Agro-ecological characters } & \multicolumn{6}{|c|}{ Locations } \\
\cline { 2 - 7 } & Shamnagar & Kaliganj & Batiaghata & Nazirpur & Sonagazi & Noakhali \\
\hline Latitude & $22.3^{\circ} \mathrm{N}$ & $22.4^{\circ} \mathrm{N}$ & $22^{\circ} 46^{\prime} \mathrm{N}$ & $22^{\circ} 34^{\prime} \mathrm{N}$ & $22^{\circ} 85^{\prime} \mathrm{N}$ & $22^{\circ} 81^{\prime} \mathrm{N}$ \\
\hline Longitude & $89.1^{\circ} \mathrm{E}$ & $89.0^{\circ} \mathrm{E}$ & $89^{\circ} 24^{\prime} \mathrm{E}$ & $89^{\circ} 90^{\prime} \mathrm{E}$ & $91^{\circ} 39^{\prime} \mathrm{E}$ & $91^{\circ} 08^{\prime} \mathrm{E}$ \\
\hline Altitude & $3 \mathrm{~m}$ & $4 \mathrm{~m}$ & $1.9 \mathrm{~m}$ & $5.2 \mathrm{~m}$ & $5.5 \mathrm{~m}$ & $6.5 \mathrm{~m}$ \\
\hline Annual rainfall $(\mathrm{mm})$ & 1710 & 1710 & 1790 & 3000 & 3302 & 3425 \\
\hline Water salinity range $\left.(\mathrm{dS} \mathrm{m})^{-1}\right)^{*}$ & $0.2-22.4$ & $0.2-17.2$ & $0.2-15.4$ & $0.0-12.5$ & $0.0-6.2$ & $0.0-4.6$ \\
\hline Mean maximum temperature & $35.5^{\circ} \mathrm{C}$ & $35.5^{\circ} \mathrm{C}$ & $35.5^{\circ} \mathrm{C}$ & $33^{\circ} \mathrm{C}$ & $34.3^{\circ} \mathrm{C}$ & $34^{\circ} \mathrm{C}$ \\
\hline
\end{tabular}




\begin{tabular}{|l|l|l|l|l|l|l|}
\hline Mean minimum temperature & $12.5^{\circ} \mathrm{C}$ & $12.5^{\circ} \mathrm{C}$ & $12.5^{\circ} \mathrm{C}$ & $11^{\circ} \mathrm{C}$ & $14.2^{\circ} \mathrm{C}$ & $15.3^{\circ} \mathrm{C}$ \\
\hline
\end{tabular}

*Electrical conductivity (EC) measured by EC meter

\section{Table 3}

The range of water salinity determined from the experimental plots over four years at the six sites.

\begin{tabular}{|l|c|c|c|c|c|c|}
\hline \multirow{2}{*}{ Year-Season } & \multicolumn{5}{|c|}{ Water salinity $\left.(\mathrm{dS} \mathrm{m})^{-1}\right)$} \\
\cline { 2 - 7 } & Shyamnagar & Kaliganj & Batiaghata & Nazirpur & Sonagazi & Noakhali \\
\hline Wet season & $0.3-0.5$ & $0.4-0.6$ & $0.5-0.8$ & $0.5-5.6$ & $0.3-1.5$ & $0.1-1.2$ \\
\hline 2010 & $2.0-3.0$ & $0.2-2.0$ & $2.0-4.0$ & $2.0-3.0$ & $0.2-3.0$ & $0.2-2.0$ \\
\hline 2011 & $1.0-4.0$ & $0.1-5.0$ & $0.2-4.6$ & $0.3-3.4$ & $0.1-2.5$ & $0.3-2.0$ \\
\hline 2012 & $0.1-4.0$ & $0.1-6.5$ & $1.0-4.3$ & $1.0-5.2$ & $0.2-2.0$ & $0.1-2.0$ \\
\hline 2013 & $2.5-16.0$ & $0.2-3.0$ & $2.0-4.6$ & $2.0-5.2$ & $0.1-3.2$ & $0.1-2.5$ \\
\hline Dry season & $2.0-15.4$ & $0.4-5.5$ & $3.0-10.2$ & $0.3-4.5$ & $0.2-3.5$ & $0.1-2.5$ \\
\hline 2010 & $1.0-6.4$ & $2.0-8.8$ & $2.0-9.3$ & $1.0-5.8$ & $0.1-2.0$ & $0.1-2.4$ \\
\hline 2011 & $2.4-10.4$ & $3.3-6.5$ & $2.2-8.4$ & $3.0-6.5$ & $0.2-3.5$ & $0.1-3.0$ \\
\hline 2012 &
\end{tabular}

\subsection{Participatory varietal selection (PVS) trials}

Promising genotypes which were later released as varieties, along with other released varieties (Table 1) were evaluated and ranked by farmers and other participants (scientists, officials from government and non-government organizations and local leaders) using the PVS approach (Islam et al., 2008b). At maturity (most of the modern varieties reached maturity stage), farmers and other participants were invited to evaluate the genotypes in each trial through a popular voting system. The votes were counted for each genotype and the characteristics of the top three chosen varieties discussed with participants, besides the reasons for selecting specific genotypes. All votes from four years at the six sites were aggregated and analyzed to reflect farmers' preferences.

\subsection{Statistical analyses}

\subsubsection{AMMI and GGE biplot analysis}


Analysis of variance was first conducted for each environment. Grain yield, duration and plant height data for all four years at the six sites were then subjected to combined analyses via additive main effect and multiplicative interaction (AMMI) analysis of variance and genotype effect and genotype $x$ environment interaction effect (GGE). In the analysis, each combination of a location and year was considered an environment. AMMI uses ANOVA to analyze the main effects (additive part) and Principal Component Analysis (PCA) to analyze the non-additive residuals by the ANOVA (Gauch, 1993). The factor explained (\%) was calculated comparing sum of square (SS) from AMMI ANOVA. When a genotype and environment have the same sign on their respective first PCA axis, their interaction is positive, if different, their interaction is negative (Tariku et al., 2013). The AMMI biplot was used to visualize the interrelationships of genotypes and environments in a graph where the aspects are plotted on the same axis. This provides a pictorial view of the transformed GEI for any interpretation. In a biplot where PCA1 is on the vertical axis and mean yield on the horizontal axis, genotypes that appear almost on a perpendicular line had similar means and those almost on a horizontal line had similar interaction patterns. Genotypes or environments with large PCA1 scores, either positive or negative had large interactions, whereas genotypes with PCA1 score of zero or nearly zero had smaller interactions (Crossa et al., 1990). The biplot of the first two PCA axes demonstrates the relative magnitude of the GEI for specific genotypes and environments.

The GGE concept was used to visually analyze the yield from multi-environment trial (MET) data. This methodology uses a biplot to show the factors (G and GE) that are important in genotype evaluation and that are also sources of variation in GEI analysis of MET data (Yan et al., 2000, 2001). GGE biplot symmetric view was used in this study to explain the 'which-wonwhere' patterns for genotypes and environments. Different polygons composed of one or several 
environment (s) and one or more genotype (s) can be used to determine which genotype(s) is performing best in which environment(s).

\section{Results}

\subsection{Wet season trials}

\subsubsection{Grain Yield}

The AMMI analysis of variance for wet season rice grain yield $\left(\mathrm{t} \mathrm{ha}^{-1}\right)$ of 8 genotypes tested in 24 environments (year-site) showed that the genotype $(G)$, environment $(E)$ and genotype $\times$ environment interaction (GEI) and its first two principal components (PCA1 and PCA2) were significant $(\mathrm{P}<0.001)$. The factors explained showed that rice grain yield was contributed mainly by genotype (72.4\%), followed by environment (11.7\%), and their interaction (7.1\%). The first two principal components (PCA1 and PCA2) explained 53.2\% and $21.7 \%$ of the GEI (Table 4). The mean grain yield of the 8 genotypes ranged from 1.85 to $5.27 \mathrm{t} \mathrm{ha}^{-1}$. The highest yielding variety was BRRI dhan54, and the lowest was Kumri, a traditional variety (Table 5). Among the 24 environments, the highest grain yield was obtained from environment E8 (2011-Kaliganj; $4.39 \mathrm{t} \mathrm{ha}^{-1}$ ), and the lowest from E4 (2010-Nazirpur; $2.69 \mathrm{t} \mathrm{ha}^{-1}$ ) (Table 5).

\section{Table 4}

AMMI analysis of variance over 24 environments (4 years x 6 sites) and eight wet season rice genotypes.

\begin{tabular}{|l|l|l|l|l|l|l|}
\hline Source & DF & $\begin{array}{l}\text { Sum of } \\
\text { squares }\end{array}$ & Mean squares & F value & $P$-value & $\begin{array}{l}\text { Explained } \\
\text { SS }(\%)\end{array}$ \\
\hline Total & 575 & 1367.9 & 2.38 & & & \\
\hline Treatment & 191 & 1248.1 & 6.53 & 20.43 & $<0.001$ & 91.2 \\
\hline Genotype & 7 & 990.6 & 141.51 & 442.37 & $<0.001$ & 72.4 \\
\hline Environment & 23 & 160.3 & 6.97 & 27.20 & $<0.001$ & 11.7 \\
\hline
\end{tabular}




\begin{tabular}{|l|l|l|l|l|c|c|}
\hline GE interaction & 161 & 97.3 & 0.60 & 1.89 & $<0.001$ & 7.1 \\
\hline PCA1 & 29 & 51.7 & 1.78 & 5.60 & $<0.001$ & 53.2 \\
\hline PCA2 & 27 & 21.2 & 0.78 & 2.46 & $<0.001$ & 21.7 \\
\hline Residuals & 105 & 24.4 & 0.23 & 0.73 & 0.973 & 1.8 \\
\hline Error & 336 & 107.5 & 0.32 & & & \\
\hline
\end{tabular}

BRRI dhan54, BRRI dhan40, BRRI dhan53, BR23 and BRRI dhan41 were generally high yielding (5.27, 4.72, 4.63, 4.12 and $4.08 \mathrm{t} \mathrm{ha}^{-1}$, respectively) (Figure 1; Table 5). In contrast, Kumri, Morichshail and Sadamota were low yielding $\left(1.85,1.97\right.$ and $2.04 \mathrm{t} \mathrm{ha}^{-1}$, respectively).

Environments E1 (2010-Shyamnagar), E7 (2011-Shyamnagar), E8 (2011-Kaliganj), E18 (2012-

Noakhali), E12 (2013-Noakhali), E24 (2013-Noakhali), E9 (2012-Batiaghata), E2 (2010-

Kaliganj), E6 (2010-Noakhali), E11 (2011-Sonagazi), E17 (2012-Sonagazi) and E22 (2013-

Nazirpur); and to some extent, E5 (2010-Sonagazi) and E10 (2011-Nazirpur) were favorable, while E20 (2013-Kaliganj), E16 (2012-Nazirpur), E23 (2013- Sonagazi), E21 (2013-Batiaghata), E14 (2012-Kaliganj), E15 (2012-Batiaghata), E3 (2010-Batiaghata), E13 (2012-Shyamnagar), E19 (2013-Shyamnagar), and E4 (2010-Nazirpur) were generally less favorable.

\section{Table 5}

Yield of eight wet season rice genotypes in 24 environments (4 years x 6 sites) and values estimated using AMMI model, mean and first two PCAs from analysis of interaction.

\begin{tabular}{|c|c|c|c|c|c|c|c|c|c|c|c|c|c|}
\hline \multirow[t]{2}{*}{ Env. } & \multirow{2}{*}{$\begin{array}{l}\text { Environment } \\
\text { (year-site) }\end{array}$} & & \multicolumn{9}{|c|}{ Genotypes Yield (t/ha) } & \multirow[t]{2}{*}{ PCA1 } & \multirow[t]{2}{*}{ PCA2 } \\
\hline & & $\begin{array}{l}\text { Biplot } \\
\text { code }\end{array}$ & BR23 & BR40 & BR41 & BR53 & BR54 & Kumri & Morichshail & Sadamota & Mean & & \\
\hline E1 & $\begin{array}{l}2010- \\
\text { Shyamnagar }\end{array}$ & Sh10 & 4.91 & 6.42 & 5.07 & 5.49 & 6.51 & 2.28 & 2.25 & 1.99 & 4.37 & -0.75 & 0.02 \\
\hline E2 & 2010-Kaliganj & K10 & 4.80 & 4.98 & 4.71 & 4.77 & 5.10 & 2.06 & 2.30 & 2.36 & 3.89 & -0.11 & 0.31 \\
\hline E3 & 2010-Batighata & B10 & 2.77 & 3.03 & 2.66 & 4.05 & 3.99 & 2.00 & 1.80 & 1.97 & 2.78 & 0.67 & -0.34 \\
\hline $\mathrm{E} 4$ & 2010-Nazirpur & Nz10 & 3.27 & 3.59 & 3.46 & 3.53 & 3.75 & 1.30 & 1.27 & 1.33 & 2.69 & 0.27 & 0.16 \\
\hline E5 & 2010-Sonagazi & So10 & 3.50 & 4.95 & 4.27 & 4.98 & 5.14 & 1.71 & 2.06 & 2.32 & 3.62 & -0.03 & -0.45 \\
\hline E6 & 2010-Noakhali & No10 & 3.86 & 4.85 & 4.21 & 5.14 & 5.65 & 1.88 & 2.17 & 2.10 & 3.73 & -0.17 & -0.32 \\
\hline E7 & $\begin{array}{l}\text { 2011- } \\
\text { Shyamnagar }\end{array}$ & Sh11 & 5.73 & 5.77 & 5.02 & 5.70 & 6.64 & 2.06 & 2.15 & 1.70 & 4.35 & -0.84 & 0.45 \\
\hline
\end{tabular}




\begin{tabular}{|c|c|c|c|c|c|c|c|c|c|c|c|c|c|}
\hline E8 & 2011-Kaliganj & K11 & 5.66 & 5.95 & 4.56 & 5.56 & 6.73 & 2.27 & 2.46 & 1.91 & 4.39 & -0.70 & 0.42 \\
\hline E9 & 2011-Batighata & B11 & 4.76 & 4.57 & 4.35 & 5.50 & 5.72 & 2.08 & 2.08 & 2.14 & 3.90 & -0.21 & 0.09 \\
\hline E10 & 2011-Nazirpur & Nz11 & 3.12 & 4.40 & 4.18 & 5.24 & 5.81 & 1.81 & 2.00 & 2.35 & 3.61 & -0.07 & -0.82 \\
\hline E11 & 2011-Sonagazi & So11 & 4.44 & 4.79 & 4.67 & 4.86 & 5.34 & 2.11 & 2.24 & 2.65 & 3.89 & 0.06 & -0.01 \\
\hline E12 & 2011-Noakhali & No11 & 5.38 & 4.39 & 4.58 & 4.77 & 6.49 & 2.19 & 2.28 & 2.86 & 4.12 & -0.13 & 0.28 \\
\hline E13 & $\begin{array}{l}2012- \\
\text { Shyamnagar }\end{array}$ & Sh12 & 3.48 & 3.42 & 3.07 & 3.51 & 3.59 & 1.83 & 2.01 & 1.63 & 2.82 & 0.61 & 0.33 \\
\hline E14 & 2012-Kaliganj & K12 & 3.85 & 3.94 & 3.35 & 3.94 & 4.07 & 1.60 & 1.88 & 1.88 & 3.06 & 0.35 & 0.26 \\
\hline E15 & 2012-Batighata & B12 & 3.46 & 3.82 & 3.22 & 3.67 & 4.12 & 2.17 & 2.11 & 2.02 & 3.07 & 0.59 & 0.11 \\
\hline E16 & 2012-Nazirpur & Nz12 & 3.68 & 4.42 & 3.87 & 4.08 & 4.89 & 2.10 & 2.20 & 2.38 & 3.45 & 0.30 & -0.10 \\
\hline E17 & 2012-Sonagazi & So12 & 3.99 & 5.60 & 4.57 & 4.96 & 5.82 & 1.49 & 1.97 & 2.07 & 3.81 & -0.50 & -0.29 \\
\hline E18 & 2012-Noakhali & No12 & 4.49 & 5.74 & 4.84 & 5.16 & 6.16 & 2.11 & 2.27 & 2.40 & 4.15 & -0.40 & -0.16 \\
\hline E19 & $\begin{array}{l}2013- \\
\text { Shyamnagar }\end{array}$ & Sh13 & 3.44 & 3.54 & 2.92 & 3.54 & 3.66 & 1.40 & 1.77 & 1.40 & 2.71 & 0.43 & 0.31 \\
\hline E20 & 2013-Kaliganj & K13 & 3.97 & 4.51 & 3.65 & 4.26 & 4.95 & 1.97 & 1.88 & 2.04 & 3.40 & 0.11 & 0.07 \\
\hline E21 & 2013-Batighata & $\mathrm{B} 13$ & 3.97 & 4.51 & 3.78 & 3.62 & 4.45 & 1.96 & 2.06 & 2.03 & 3.30 & 0.32 & 0.29 \\
\hline E22 & 2013-Nazirpur & Nz13 & 3.60 & 4.76 & 4.18 & 4.76 & 5.50 & 2.06 & 2.03 & 2.96 & 3.73 & 0.16 & -0.52 \\
\hline E23 & 2013-Sonagazi & So13 & 3.93 & 4.44 & 3.48 & 3.87 & 4.25 & 1.80 & 1.67 & 1.86 & 3.16 & 0.23 & 0.28 \\
\hline \multirow[t]{5}{*}{ E24 } & 2013-Noakhali & No13 & 4.00 & 5.46 & 4.78 & 4.87 & 6.17 & 2.16 & 2.35 & 2.58 & 4.05 & -0.20 & -0.39 \\
\hline & Mean & & 4.12 & 4.72 & 4.08 & 4.63 & 5.27 & 1.85 & 1.97 & 2.04 & 3.58 & & \\
\hline & $\operatorname{LSD}_{0.05}$ & & & & & & & & & & 0.30 & & \\
\hline & PCA1 & & -0.28 & -0.72 & -0.33 & -0.34 & -0.99 & 0.90 & 0.79 & 0.96 & & & \\
\hline & PCA2 & & 1.38 & -0.03 & -0.12 & -0.49 & -0.46 & 0.13 & 0.09 & -0.51 & & & \\
\hline
\end{tabular}

Since, PCA2 scores were also important (21.77\% of G x E SS) in explaining the genotype $\times$ environment interaction, the ballot of the first two PCAs was also used to demonstrate the relative magnitude of the GEI for specific genotypes and environments (Figure 2). The environments were grouped into four sections: the best genotypes with respect to E1, E18, E17, E10, E22, E24, E5, E7 and E8 were BRRI dhan40, BRRI dhan41, BRRI dhan53 and BRRI dhan54. The traditional varieties Kumri, Morichshail and Sadamota performed better in E13, E15, E16, E21, E19, E4, E14 and E23 than in other sites, though their yield still remain significantly lower than that of the modern varieties. BR23 was the best in E2 and E12. 


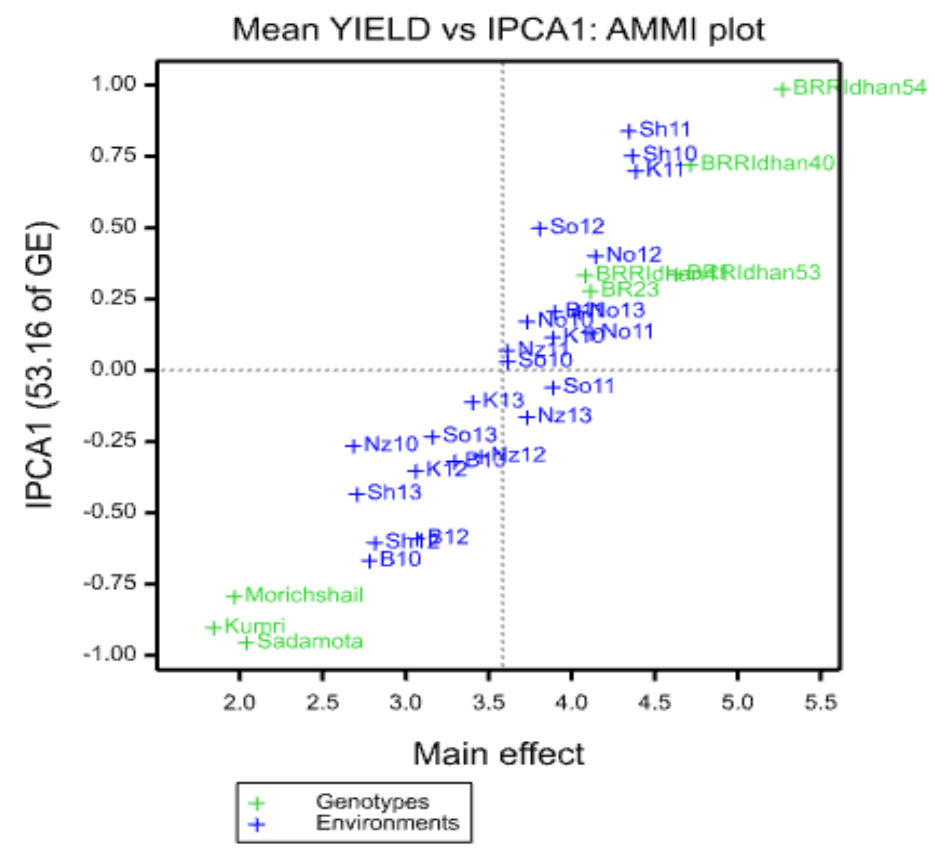

Fig. 1. AMMI biplot for the primary component of interaction (PC1) and mean yield (t/ha) or main effect of eight wet season rice genotypes. The vertical line at the center of the biplot is the general grand mean. Varieties are shown in green font whereas environments are in blue font.

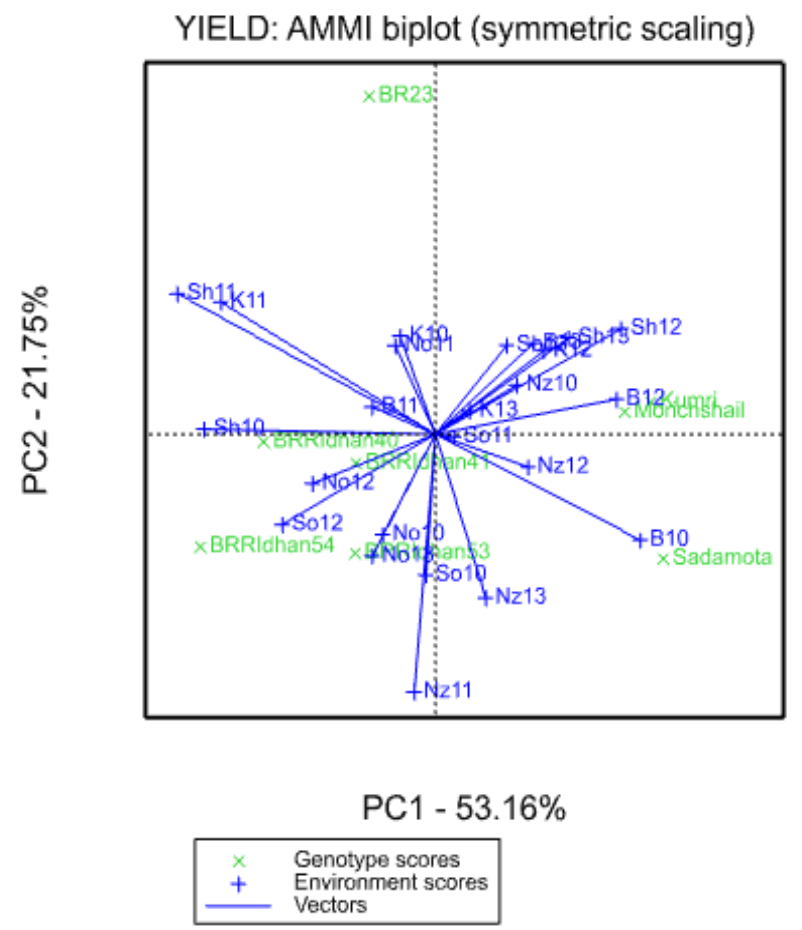


Fig. 2. AMMI biplot for genotype by environment interaction of the wet season rice cultivars over four years and six sites, showing the effects of primary and secondary principal components (PC1 and PAC, respectively). Varieties are shown in green font whereas environments are in blue font.

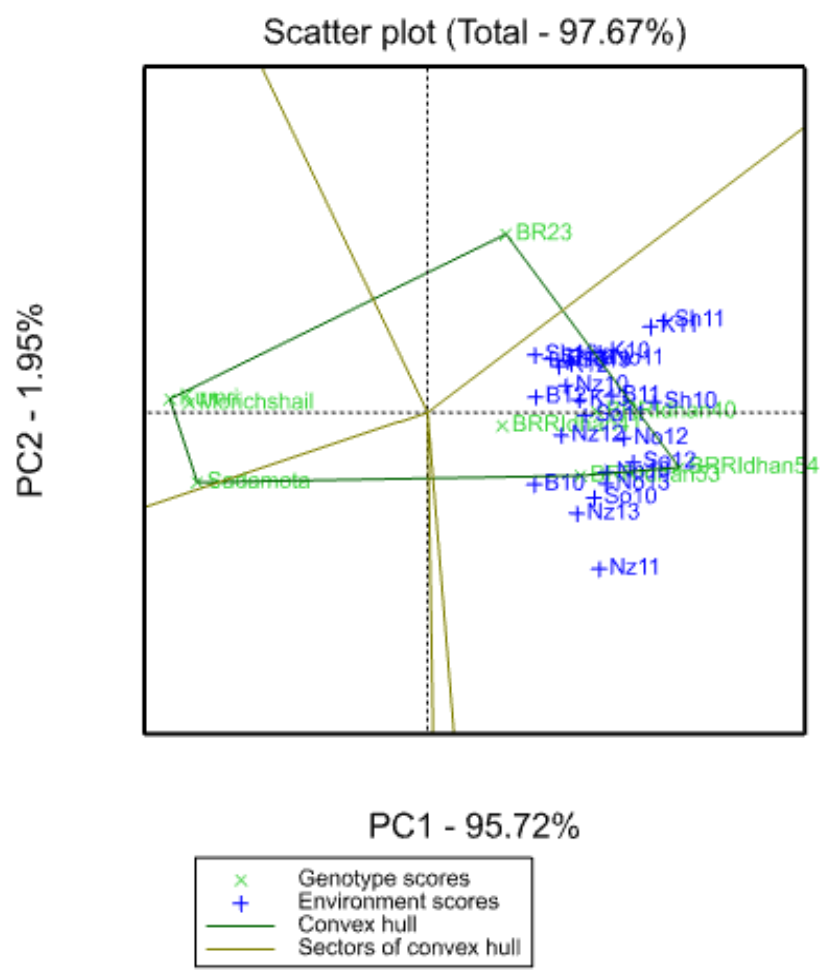

Fig. 3. Polygon views of the GGE biplot based on symmetrical scaling of wet season rice cultivars for the 'which-won-where' patterns for genotypes and environments. Varieties are shown in green font whereas environments are in blue font.

The polygon view of a GGE biplot explicitly displays the 'which-won-where' pattern, and, hence, is a summary of the GEI pattern of a multi environment trial (MET) data set (Figure 3). The lines divide the biplot into sectors, but all environments grouped into one main sector. The vertex genotype for this sector was BRRI dhan54, suggesting it is the highest yielding for all these environments, followed by BRRI dhan40, BRRI dhan53 and BRRI dhan41. BR23 was 
located in a different sector but is the highest yielding variety in this sector. The three low yielding traditional varieties were in a third sector with no environments. The highest yielding and most stable genotype was BRRI dhan54 followed by BRRI dhan40, BRRI dhan53 and BRRI dhan41.

\subsubsection{Duration}

The analysis of variance for overall duration (based on 4 years $x 6$ sites) of the 8 wet season genotypes reflected significant differences between the genotypes $(\mathrm{P}<0.001)$. The site mean for duration was $149 \mathrm{~d}$ with standard deviation of 17.6. The longest duration was that of Kumri (170 d), a traditional photoperiod sensitive variety; followed by Morichshail (168 d) and Sadamota (166 d), and among the released high yielding varieties (HYVs) the longest duration was that of BR23 (152 d) followed by BRRI dhan41 (143 d), BRRI dhan40 (141 d) and BRRI dhan54 (133 d); and the shortest was BRRI dhan53 (120 d) (Table 6).

\subsubsection{Plant height}

Genotypes also differ significantly $(\mathrm{P}<0.001)$ in their plant height at maturity. The site mean for plant height was $139 \mathrm{~cm}$ with standard deviation of 48 . The tallest variety was Morichshail $(176 \mathrm{~cm})$, followed by Kumri $(164 \mathrm{~cm})$ and Sadamota $(154 \mathrm{~cm})$, and the tallest of the HYVs was BRRI dhan40 $(135 \mathrm{~cm})$ followed by BRRI dhan41 $(134 \mathrm{~cm})$, BRRI dhan54 (118 $\mathrm{cm})$ and BR23 $(115 \mathrm{~cm})$, with the shortest BRRI dhan53 (113 cm) (Table 6).

\subsubsection{Farmers' preferences}

Farmers' preferences were calculated based on votes (choices) received for each rice genotype. The most preferred variety was BRRI dhan53 (174 votes) for the wet season, followed by BRRI dhan54 (152 votes), BRRI dhan40 (74 votes), BRRI dhan41 (42 votes), and BR23 (25 votes). 
These modern varieties were highly preferred compared to the traditional varieties Sadamota,

Moricshail and Kumri, which received 1, 2 and zero votes, respectively (Table 6).

Table 6

Mean growth duration, plant height and total votes obtained for each variety through PVS of wet season rice varieties. Data are means of four years and six sites.

\begin{tabular}{|l|c|c|c|}
\hline \multicolumn{1}{|c|}{ Varieties } & $\begin{array}{c}\text { Growth } \\
\text { duration (days) }\end{array}$ & $\begin{array}{c}\text { Plant height } \\
\mathbf{( c m )}\end{array}$ & $\begin{array}{c}\text { Total votes obtained } \\
\text { through PVS }\end{array}$ \\
\hline BR23 & 152 & 115 & 25 \\
\hline BRRI dhan40 & 141 & 135 & 74 \\
\hline BRRI dhan41 & 143 & 135 & 42 \\
\hline $\begin{array}{l}\text { BRRI dhan53 (BR5778-156-1-3- } \\
\text { HR14) }\end{array}$ & 120 & 114 & 174 \\
\hline BRRI dhan54 (BR5999-82-3-2-HR1) & 132 & 118 & 152 \\
\hline Kumri & 171 & 164 & 0 \\
\hline Morichshail & 168 & 176 & 2 \\
\hline Sadamota & 166 & 154 & 1 \\
\hline LSD Value & 1.6 & 14.0 & - \\
\hline
\end{tabular}

\subsection{Dry season trials}

\subsubsection{Grain yield}

The AMMI analysis of variance for the 5 dry season rice grain yield ( $\left.\mathrm{t} \mathrm{ha}^{-1}\right)$ indicated that $\mathrm{G}, \mathrm{E}$ and GEI and its first two principal components (PCA1 and PCA2) were significant $(\mathrm{P}<0.001)$. The results clearly reflected large environmental effects during the dry season (Table 7). The mean grain yield of the 5 modern varieties ranged from 4.90 to $6.20 \mathrm{t} \mathrm{ha}^{-1}$. The highest yielding variety was BRRI dhan47, and the lowest was BRRI dhan28 (Table 8). Among the 24 environments, the highest grain yield was obtained from environment E17 (2012-Sonagazi; 7.73 $\left.\mathrm{t} \mathrm{ha}^{-1}\right)$, and the lowest in 2013 in Shyamnagar $\left(\mathrm{E} 19 ; 2.91 \mathrm{t} \mathrm{ha}^{-1}\right)$ (Table 8). 


\section{Table 7}

AMMI analysis of variance over twenty four environments (4 years x 6 sites) and five dry season rice genotypes.

\begin{tabular}{|l|c|c|c|c|c|c|}
\hline Source & DF & $\begin{array}{l}\text { Sum of } \\
\text { squares }\end{array}$ & Mean squares & F Value & Pr.F & $\begin{array}{c}\text { Explained } \\
\text { SS (\%) }\end{array}$ \\
\hline Total & 359 & 956.1 & 2.663 & & & \\
\hline Treatment & 119 & 851.9 & 7.159 & 16.84 & $<0.001$ & 89.1 \\
\hline Genotype & 4 & 87.6 & 21.891 & 51.49 & $<0.001$ & 9.2 \\
\hline Environment & 23 & 698.3 & 30.360 & 64.63 & $<0.001$ & 73.0 \\
\hline GE interaction & 92 & 66.1 & 0.718 & 1.69 & 0.0013 & 6.9 \\
\hline \multicolumn{1}{|c|}{ PCA1 } & 26 & 47.6 & 1.831 & 4.31 & $<0.001$ & 72.1 \\
\hline PCA2 & 24 & 12.1 & 0.504 & 1.19 & 0.2586 & 18.3 \\
\hline Residuals & 42 & 6.4 & 0.151 & 0.36 & 0.9999 & 0.7 \\
\hline Error & 192 & 81.6 & 0.425 & 192 & 81.6 & \\
\hline
\end{tabular}

\section{Table 8}

Yield of five dry season rice genotypes over 24 environments (4 years x 6 sites) and values estimated using AMMI model, mean and first two PCAs from analysis of the interaction.

\begin{tabular}{|c|c|c|c|c|c|c|c|c|c|c|}
\hline \multirow[t]{2}{*}{ Env. } & \multirow{2}{*}{$\begin{array}{l}\text { Environment } \\
\text { (year-site) }\end{array}$} & \multirow[b]{2}{*}{$\begin{array}{l}\text { Biplot } \\
\text { code }\end{array}$} & \multicolumn{6}{|c|}{ Genotypes Yield (t/ha) } & \multirow[t]{2}{*}{ PCA1 } & \multirow[t]{2}{*}{ PCA2 } \\
\hline & & & BINA8 & $\mathrm{BR} 28$ & BR47 & BR55 & BR61 & Mean & & \\
\hline E1 & $\begin{array}{l}2010- \\
\text { Shyamnagar }\end{array}$ & Sh10 & 4.30 & 2.62 & 4.73 & 3.34 & 4.41 & 3.88 & 0.34 & 0.31 \\
\hline E2 & 2010-Kaliganj & K10 & 7.35 & 6.50 & 7.76 & 7.05 & 6.47 & 7.03 & -0.31 & 0.73 \\
\hline E3 & 2010-Batighata & $\mathrm{B} 10$ & 6.30 & 6.44 & 7.07 & 6.62 & 7.17 & 6.72 & -0.29 & -0.21 \\
\hline E4 & 2010-Nazirpur & Nz10 & 6.50 & 6.59 & 7.11 & 6.86 & 6.18 & 6.65 & -0.59 & 0.38 \\
\hline E5 & 2010-Sonagazi & So10 & 5.95 & 6.49 & 6.76 & 6.58 & 6.72 & 6.50 & -0.50 & -0.19 \\
\hline E6 & 2010-Noakhali & No10 & 6.01 & 6.44 & 6.72 & 6.59 & 6.08 & 6.37 & -0.64 & 0.16 \\
\hline E7 & $\begin{array}{l}\text { 2011- } \\
\text { Shyamnagar }\end{array}$ & Sh11 & 4.70 & 1.85 & 5.10 & 2.83 & 5.72 & 4.04 & 1.13 & -0.05 \\
\hline $\mathrm{E} 8$ & 2011-Kaliganj & K11 & 5.96 & 5.78 & 6.65 & 6.07 & 6.48 & 6.19 & -0.24 & -0.01 \\
\hline E9 & 2011-Batighata & B11 & 3.46 & 2.39 & 4.08 & 2.90 & 4.36 & 3.44 & 0.27 & -0.13 \\
\hline
\end{tabular}




\begin{tabular}{|l|l|r|r|r|r|r|r|r|r|r|}
\hline E10 & 2011-Nazirpur & Nz11 & 5.96 & 6.39 & 6.76 & 6.51 & 6.69 & 6.46 & -0.46 & -0.16 \\
\hline E11 & 2011-Sonagazi & So11 & 6.54 & 7.41 & 7.56 & 7.34 & 8.52 & 7.47 & -0.32 & -0.81 \\
\hline E12 & 2011-Noakhali & No11 & 6.23 & 6.14 & 7.06 & 6.35 & 7.72 & 6.70 & -0.02 & -0.50 \\
\hline E13 & $\begin{array}{l}\text { 2012- } \\
\text { Shyamnagar }\end{array}$ & Sh12 & & & & & & & & \\
\hline E14 & 2012-Kaliganj & K12 & 3.53 & 4.96 & 6.22 & 5.33 & 6.46 & 5.70 & 0.05 & -0.19 \\
\hline E15 & 2012-Batighata & B12 & 3.76 & 3.07 & 4.41 & 3.48 & 4.49 & 5.39 & 0.66 & 0.01 \\
\hline E16 & 2012-Nazirpur & Nz12 & 5.17 & 3.25 & 5.61 & 4.01 & 5.58 & 4.73 & 0.53 & 0.18 \\
\hline E17 & 2012-Sonagazi & So12 & 7.72 & 6.99 & 8.33 & 7.43 & 8.20 & 7.73 & 0.00 & 0.05 \\
\hline E18 & 2012-Noakhali & No12 & 7.07 & 6.43 & 7.65 & 6.87 & 7.22 & 7.05 & -0.13 & 0.21 \\
\hline E19 & 2013- & Sh13 & & & & & & & & \\
& Shyamnagar & & 3.07 & 1.73 & 3.64 & 2.32 & 3.81 & 2.91 & 0.36 & -0.03 \\
\hline E20 & 2013-Kaliganj & K13 & 5.04 & 4.09 & 5.60 & 4.60 & 5.41 & 4.95 & 0.07 & 0.12 \\
\hline E21 & 2013-Batighata & B13 & 3.42 & 2.49 & 4.01 & 2.98 & 3.91 & 3.36 & 0.10 & 0.07 \\
\hline E22 & 2013-Nazirpur & Nz13 & 5.09 & 4.14 & 5.68 & 4.64 & 5.61 & 5.03 & 0.12 & 0.05 \\
\hline E23 & 2013-Sonagazi & So13 & 6.43 & 6.02 & 7.05 & 6.39 & 6.68 & 6.51 & -0.21 & 0.14 \\
\hline E24 & 2013-Noakhali & No13 & 6.26 & 5.60 & 6.90 & 6.01 & 6.94 & 6.34 & 0.03 & -0.06 \\
\hline & Mean & & 5.57 & 4.90 & 6.20 & 5.32 & 6.14 & 5.63 & & \\
\hline & LSD & & & & & & & 0.28 & & \\
\hline & PCA1 & & 0.67 & -1.31 & 0.45 & -0.80 & 0.98 & & & \\
\hline & PCA2 & 0.81 & -0.29 & 0.41 & 0.11 & -1.04 & & & \\
\hline
\end{tabular}

AMMI analysis indicated that grain yields of BRRI dhan47 and BRRI dhan61 were generally the highest (6.20 and $6.14 \mathrm{t} \mathrm{ha}^{-1}$, respectively; Figure 4; Table 8). BRRI dhan55 and BRRI dhan28 were low yielding (5.32 and $4.90 \mathrm{t} \mathrm{ha}^{-1}$, respectively). Sonagazi and Noakhali sites were generally more favourable than Kaliganj and Shyamnagar (Figure 4).

Figure 5 showed the relative magnitude of the GEI for specific genotypes and environments. The environments fell into four sections: the best genotypes in E14, E16, E1, and E2 were BRRI dhan47 and BINA dhan8. BRRI dhan61 was the best in E9, E19, E7, E3 and E12. BRRI dhan28 and BRRI dhan55 were best in E5 and E10, E3, E8, E11, E6, E4, E23 and E22. 


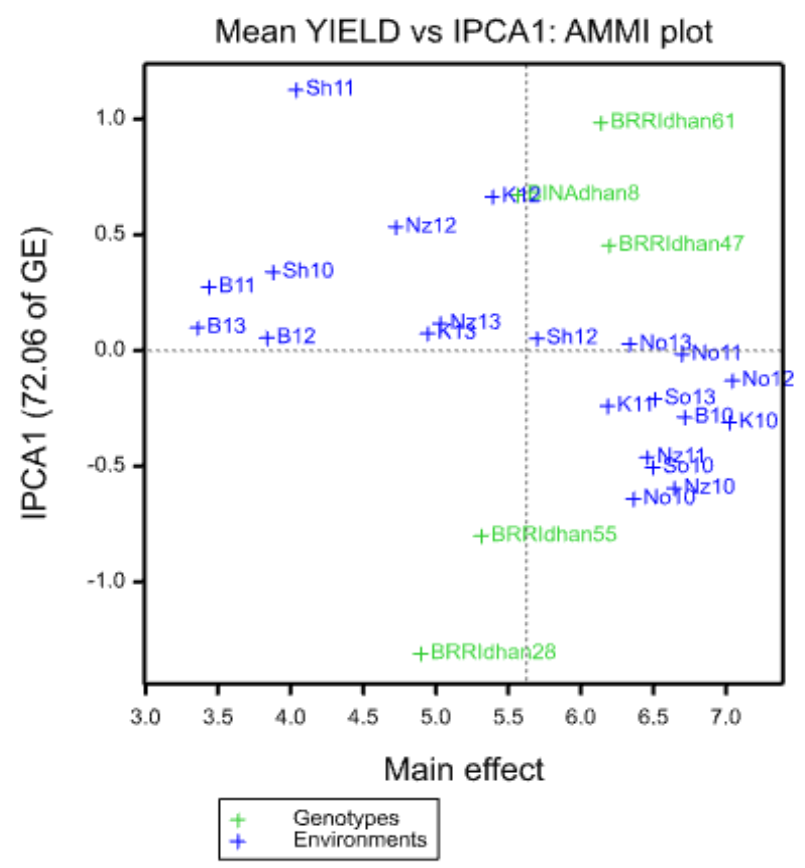

Fig 4. AMMI biplot for the primary components of interaction $(\mathrm{PC} 1)$ and yield $\left(\mathrm{t} \mathrm{ha}^{-1}\right)$ or main effect of dry season rice varieties. The vertical line at the centre of the biplot is the grand mean. Varieties are shown in green font whereas environments are in blue font.

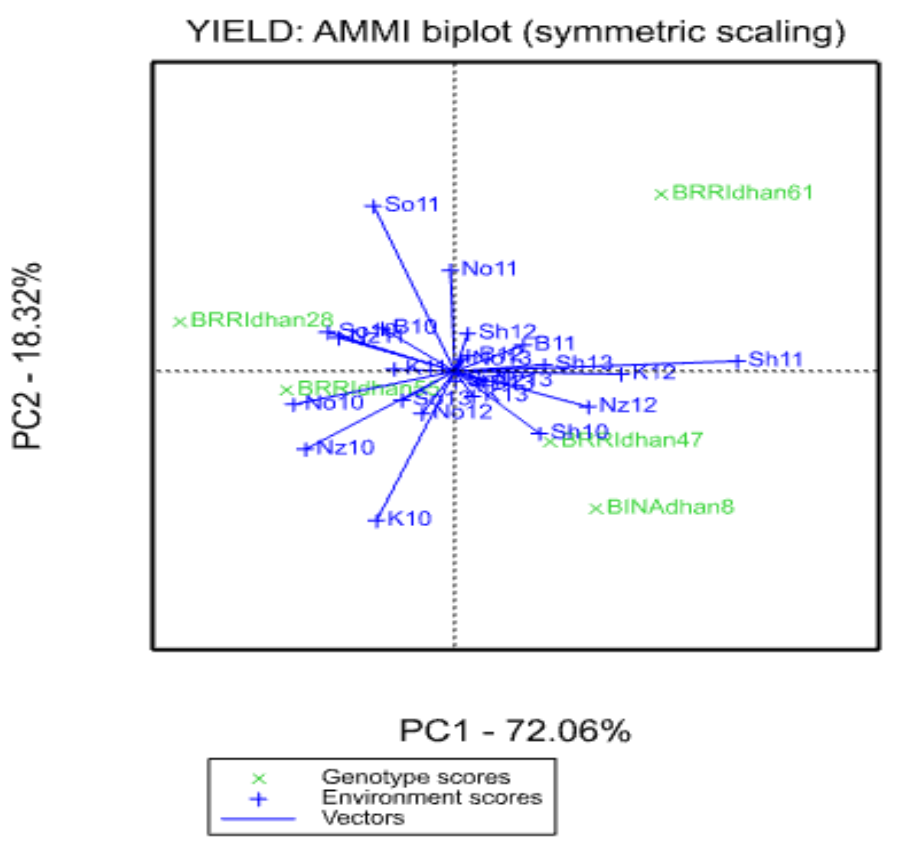


Fig. 5. AMMI biplot for genotype by environment interaction of the dry season rice cultivars over four years at the six sites, showing the effects of primary and secondary principal components (PC1 and PC2, respectively).

The 'which-won-where' pattern is shown in Figure 6. The 3 rays divide the biplot into 4 sectors, but the environments fall into 3 of them. The GGE biplot indicates that BRRI dhan61 and BRRI dhan47 had the highest yields in most environments. BRRI dhan28 and the moderately salt tolerant BRRI dhan55 were generally low yielding due to their sensitivity to salinity. BRRI dhan 47 and BRRI dhan 61 had the highest and more stable grain yield across environments.

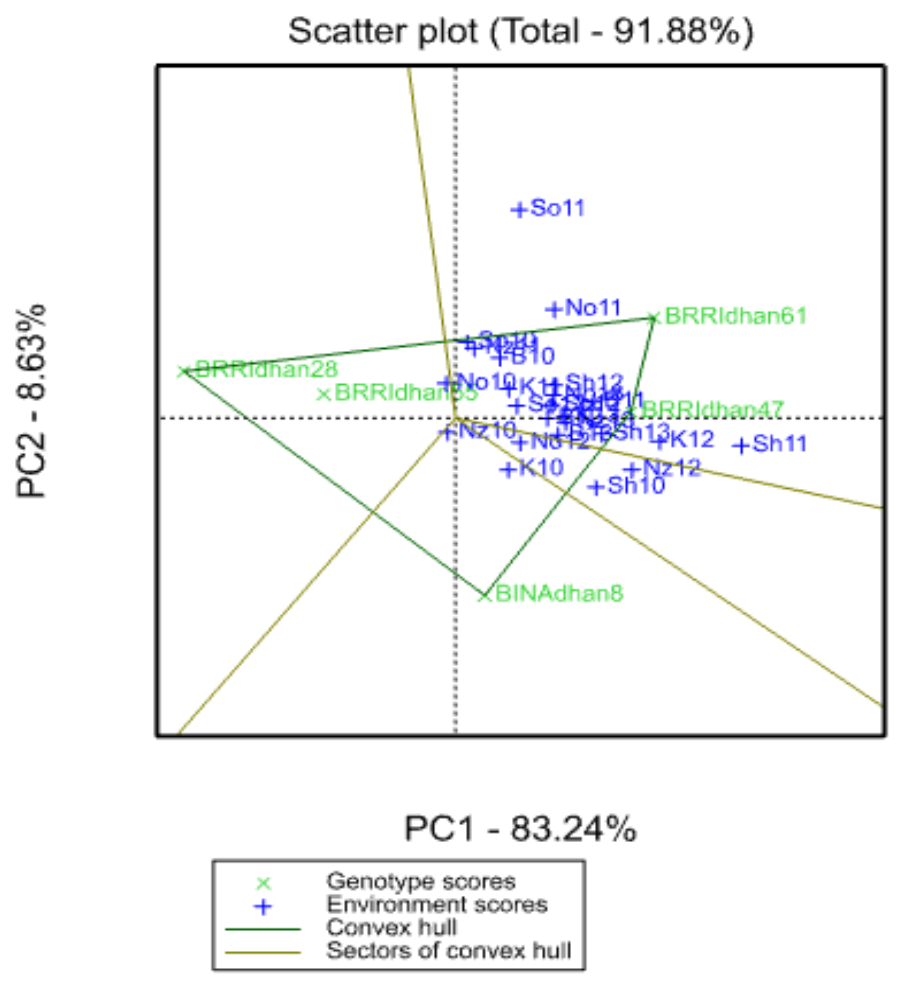

Fig. 6. Polygon views of the GGE biplot based on symmetrical scaling for 'which-won-where' pattern of dry season rice genotypes and environments. The blue and green fonts stand for environments and genotypes, respectively. 


\subsubsection{Duration to maturity}

The 5 genotypes differed significantly in their duration to maturity $(\mathrm{P}<0.001)$. The site mean for duration was $145 \mathrm{~d}$ with standard deviation of 5.35. The longest growth duration was that of BRRI dhan55 (149 d), followed by BRRI dhan61 and BINA dhan8 (146 d), BRRI dhan47 (145 d), and then BRRI dhan28 (140 d) (Table 9).

\subsubsection{Plant height}

Genotypic differences in plant height were also significant $(\mathrm{P}<0.001)$. The site mean for plant height was $104 \mathrm{~cm}$ with standard deviation of 12.4. The tallest variety was BRRI dhan28 followed by BRRI dhan47 and BINA dhan8. The shortest variety was BRRI dhan61 (Table 9).

\section{Table 9}

Mean growth duration, plant height and total votes obtained for each variety through PVS for dry season rice varieties. Data are means of six sites over four years.

\begin{tabular}{|l|c|c|c|}
\hline \multicolumn{1}{|c|}{ Varieties } & $\begin{array}{c}\text { Growth } \\
\text { duration (days) }\end{array}$ & $\begin{array}{c}\text { Plant height } \\
\mathbf{( c m )}\end{array}$ & $\begin{array}{c}\text { Total votes obtained } \\
\text { through PVS }\end{array}$ \\
\hline BRRI dhan28 & 146 & 107 & 88 \\
\hline BRRI dhan47 & 140 & 109 & 345 \\
\hline BINA dhan8 (IR66946-3R-149-1-1) & 145 & 108 & 15 \\
\hline BRRI dhan55 (IR73678-6-9-B) & 149 & 100 & 28 \\
\hline BRRI dhan61 (BR7105-4R-2) & 146 & 92 & 164 \\
\hline LSD Value & 1.03 & 2.9 & - \\
\hline
\end{tabular}

\subsubsection{Farmers' preferences}


The most preferred variety was BRRI dhan47 (345 votes) followed by BRRI dhan61 and BRRI dhan28 and the least preferred were BRRI dhan55 and BINA dhan8 (15 votes) (Table 9).

\section{Discussion}

The coastal areas of South Bangladesh represent significant rice production area for the country, but subject to several abiotic stresses. Several high-yielding salt-tolerant varieties were released for this region in recent years, but their adaptability to local conditions and suitability based on farmers' preferences across the region have not been rigorously evaluated. An extensive $\mathrm{G} \times \mathrm{E}$ analysis was conducted to identify the most suitable rice varieties for this coastal region for both dry and wet seasons. To our knowledge, this is the first attempt to evaluate and rank these varieties across the region to facilitate setting strategies and support for seed production and dissemination of broadly adapted and preferred varieties to farmers in the region.

In the wet season, the genotypic contribution was considerably higher than the effect of the environment on grain yield. There were little differences between locations as reflected by the high correlations between site and year; and very small environment and GEI effects were detected. BRRI dhan54 was the highest yielding and stable variety, followed by BRRI dhan40, BRRI dhan53, BR23 and the lowest yields were from the traditional rice varieties (Table 5). The three traditional varieties included in the evaluation possess numerous undesirable traits, including coarse grains, longer duration, high photoperiod sensitivity, taller stature, moderate sensitivity to salt stress and low grain yield. However, these old varieties are still popular among farmers because of their relatively taller seedlings at transplanting and their waterlogging tolerance, both desired in stagnant flood areas, besides lack of better varieties. The results of the study highlighted the superior performance of the newly released high yielding varieties (HYVs), 
which also had good grain type, medium to short growth duration, medium stature, and salt tolerance. Although we were not able to thoroughly monitor water depth at all sites in this study, and given these regions typically encounter stagnant floods for most of the season, we deduce that these new HYVs also possess reasonable tolerance to SF, since these varieties were evaluated with farmers in some of these areas in the region before release. Several of the landraces collected from this region were found to be tolerant of stagnant flooding (Vergara et al., 2014)

Among the 24 environments, the highest grain yield was obtained from Kaliganj in 2011. Shyamnagar was high yielding sites for several years, possibly because of higher rainfall in the wet season during these years resulting in lower salt stress, even though this site was historically recognized for its higher and wider range of soil and water salinity (Table 2). In contrast, the lowest yield was obtained from Nazirpur in 2010, suggesting this environment is less favourable. The traditional varieties were consistently low yielding compared with the HYVs in all trials, though they had positive interactions in some environments especially in Batiaghata in 2010 and 2012 (Figures 1 and 2). Since salinity differed between these sites and years, the results suggest that SF affected the performance of these trials and reduced the yield of the HYVs but not as much in the traditional varieties. This is one of the main reasons farmers like to grow traditional varieties in these areas despite their lower attainable yield.

The tallest variety was Morichshail, followed by Kumri and Sadamota (Table 6). From our field observations, these traditional varieties were susceptible to lodging and their yields are the lowest, but they had the advantage of tolerating SF for 2-3 months. Recent studies showed that new varieties suitable for such stagnant flood conditions need to combine several traits including moderate elongation $\left(<2 \mathrm{~cm} \mathrm{~d}^{-1}\right)$, ability to produce sufficient number of productive 
tillers and thickening of their culms under SF to avoid lodging (Singh et al., 2011; Vergara et al., 2014, Kato et al., 2014). These findings provide valuable information for breeders, since farmers would prefer new varieties with SF tolerance in these tropical coastal zones. Varieties such as BRRI dhan40 $(135 \mathrm{~cm})$ and BRRI dhan41 had medium height but they could not tolerate water logging. More recently released varieties such as BRRI dhan54 $(118 \mathrm{~cm})$, and BRRI dhan53 (114 $\mathrm{cm}$ ) had medium growth duration, medium slender grains and moderate tolerance to SF for over one month. Apparently, salt tolerant varieties with better tolerance of SF are needed for the wet season in this region.

Farmers' preferences in ranking these varieties were generally consistent with yield data. For example, the most preferred variety by farmers and other participants were BRRI dhan53 (174 votes) and BRRI dhan54 (152 votes), which were consistently the highest yielding varieties. The traditional varieties received the least votes. These results revealed that most farmers preferred the characteristics of the current HYVs, such as shorter duration, medium stature, medium slender grain type and reasonable salinity and SF tolerance. Future varieties however, need to have higher tolerance of SF and taller seedlings during transplanting in the wet season.

Vast areas of coastal Bangladesh remain fallow during the wet season. The main reasons for this fallow period is the lack of suitable short duration, salt and SF tolerant varieties, as salinity is usually high at the beginning of the wet season and SF prevails for most of the monsoon season. If farmers could harvest their wet season rice crop one month earlier, then they can establish an early rabi (non-rice dry season) crop or boro (dry season rice) crop, and they could harvest it earlier. This change in cropping pattern will reduce the risk from natural calamities (e.g. cyclone, storm, tidal surges), which often happen from mid April to May in this region. Therefore these short duration varieties with moderate salinity and SF tolerance can be 
extremely beneficial for rice farmers during the wet season in these coastal zones of South Bangladesh as well as in other coastal zones in South and Southeast Asia.

The results from the dry season trials were surprisingly different from those of the wet season. The environmental contribution was much higher than the genotypic effect on yield of dry season rice varieties. These results revealed that among the environmental factors, soil and water salinity is the most important, as it negatively affected grain yield of these varieties. The highest yielding variety was BRRI dhan47, followed by BRRI dhan61, BINA dhan8 and BRRI dhan55; and the lowest was BRRI dhan28, which is a dry season popular variety but salt sensitive. These results clearly indicated that grain yield is highly dependent on salinity tolerance. For example, BRRI dhan47, BINA dhan8 and BRRI dhan61 with SES scores of 3 (Table 1) produced higher yields, while the moderately tolerant BRRI dhan55 had intermediate yield and the sensitive BRRI dhan 28 had the lowest yield, even though it is the most popular variety in favorable areas during the dry season in Bangladesh. Among the 24 environments, the highest grain yields were generally produced in Sonagazi and Noakhali, although in some years Kaliganj and Batighata also showed high trial mean yields when salinity was low. These results suggest that these environments are suitable for growing rice in the dry season provided varieties with high tolerance of salt stress were used and freshwater is available. Farmers in most of these areas are abstaining from growing rice during the dry season fearing losses due to salt stress. Water salinity in the higher yielding sites was $<4 \mathrm{dS} \mathrm{m}^{-1}$ during the whole cropping season (Table 3). The lowest yielding sites were in Batiaghata and for some years in Shyamnagar; the salinity range in these sites was 2-16 $\mathrm{dS} \mathrm{m}^{-1}$, which reflects the association of lower yields and high salt stress. 
BRRI dhan47 and BRRI dhan61 were the highest yielding and stable varieties.

Furthermore BRRI dhan47 had the lowest interaction with environments, suggesting this variety is more stable and widely adapted, while BRRI dhan61, which showed some high GEI, is more suitable in specific environments. BRRI dhan 47 was also the most preferred variety, followed by BRRI dhan61, then BRRI dhan28, BRRI dhan55, and BINA dhan8. Based on our discussion with farmers, they selected BRRI dhan47, the first released salt tolerant variety for the dry season in Bangladesh, because of its medium growth duration, medium stature, and bold grains. BINA dhan8 has similar characteristics and both varieties have negative characters (according to farmers), including their bold-type grain and shattering tendency when over mature. Despite these negative traits, most farmers voted for BRRI dhan 47 for its high salt tolerance. However BRRI dhan61, the newest variety commercialized in the region in 2013, is also becoming popular for its medium slender grains and is non-shattering, but still voted as the second choice by farmers. Although BRRI dhan28 is salt sensitive and had low yields in most of the environments, it was voted third due to its good grain quality and shorter duration. The information gathered from these studies will help focus resources and efforts to produce sufficient and high quality seeds of the high ranking varieties and also guide future breeding activities to develop varieties that are broadly adapted to these complex conditions of the coastal zone of south Bangladesh, but also meet the grain and eating quality preferences of local farmers and consumers. These results could potentially be expanded to other tropical deltas facing similar conditions in South and Southeast Asia.

\section{Conclusions}


Two different sets of wet and dry season rice varieties developed for the coastal region of Bangladesh were evaluated at six different sites over four years. The results showed that GEI is important for grain yield. Moreover, the genotypic and environmental contributions were different for the wet and dry seasons. Environmental effects were extremely important during the dry season due to higher salt stress, whereas genotypic effects were dominant during the wet season, where tolerances of both salinity and SF need to be considered. BRRI dhan47 is widely adapted in most of the environments of coastal Bangladesh in the dry season, followed by BRRI dhan61. The later has better grain quality and is non-shattering, hence could be recommended for most locations, especially in areas where salt stress is high. The short-duration varieties, BRRI dhan53 and BRRI dhan54, which also are moderately tolerant of SF are suitable in most sites during the wet season. More emphasis should be devoted in future breeding programs to develop varieties with wider adaptation within each season based on the suite of traits identified in this study, including grain type preferences. We recommend that varieties for the dry season should have higher salinity tolerance, together with shorter duration, while wet-season varieties should combine salinity tolerance with tolerance of stagnant flooding and relatively shorter duration. For both seasons, emphasis should also be placed on improving grain quality to match local and market preferences.

\section{Author contribution statement}

MRI designed the experiments; MRI, MRAS, NS and MAR conducted the trials; MRI, and BC analyzed the data; MRI, BC and AMI drafted the manuscript. GBG and AMI reviewed the manuscript. All authors read and approved the manuscript before submission. 


\section{Conflict of interest statement}

None declared

\section{Acknowledgement}

Funding for breeding and evaluation of stress tolerant rice varieties was partially provided by STRASA (Stress Tolerant Rice for Africa and South Asia) funded by the Bill and Melinda Gates foundation, the Generation Challenge Program (GCP), the Challenge Program on Water and Food (CPWF) and the "Dissemination of salt tolerant rice varieties" funded by the Danish International Development Agency (DANIDA). We thank BRRI and IRRI for supporting this research.

\section{References}

Annicchiarico P. and Perenzin M., 1994. Adaptation patterns and definition of macro environment for selection and recommendation of common wheat in Italy. Plant Breed, $113: 197-225$.

BRRI, 2013. Modern Rice Cultivation. $17^{\text {th }}$ Edition, Gazipur, Bangladesh. Pp 6-12.

BBS, 2013. Yearbook of Agricultural Statistics of Bangladesh, Bangladesh Bureau of Statistics (BBS). Sher-e-Bangla Nagar, Dhaka-1207, Bangladesh.

Crossa, J., 1990. Statistical analysis of multi-location trials. Adv Agron, 44:55-85.

Crossa J., Gauch H.G. and Zobel R.W., 1990. Additive main effects and multiplicative interaction analysis of two international maize cultivar trials. Crop Sci, 30: 493-500.

Ding, M., Tier B. and Yan W., 2007. Application of GGE biplot analysis to evaluate genotype (G), environment (E) and GxE interaction on P. radiata: case study. Australasian Forest Genetics Conference, 11 - 14 April 2007, the Old Woolstore, Hobart, Tasmania, Australia. 
Gauch, H.G., 1993. Matmodel version2.0. AMMI and related analysis for two-way data matrices. Micro computer power, Ithaca, New York, USA.

Gauch, H.G. and Zobel, R.W., 1997. Identifying mega-environments and targeting genotypes. Crop Sci. 37:311-326.

Gauch, H.G., 2006. Statistical analysis of yield trials by AMMI and GGE. Crop Sci. 46:14881500.

Islam M.R., Rahman M.S. and Salam M.A., 2008a. Coastal Saline Environment and Rice Variety Development in Bangladesh. Eco-Friendly Agriculture Journal. 1 (1): 37-47.

Islam, M.R, Salam M.A., Bhuiyan M.A.R., Rahman M.A. and Gregorio G.B.. 2008b. Participatory variety selection for salt tolerant rice. Intl. J. BioRes. 4 (3): 21-25.

Islam, M.R., Islam M.M. and Gregrio G.B., 2013. Salt-tolerant rice varieties released in Bangladesh. STRASA News, International Rice Research Institute, Jan-March, 2013. 6 (1): 6-7.

Islam M.R. and Gregorio G.B., 2013. Progress of salinity tolerant rice variety development in Bangladesh. SABRAO Journal of Breeding and Genetics. 45 (1): 21-30.

Ismail A.M. and Mackill D.J. 2014. Response to flooding: submergence tolerance in rice. In: Jackson M, Ford-Lloyed B, Parry M, editors. Plant Genetic Resources and Climate Change - a 21st Century Perspective. p 251-269. CAB International, UK.

Ismail, A.M., Platten, J.D. and Miro, B. 2013. Physiological bases of tolerance of abiotic stresses in rice and mechanisms of adaptation. ORYZA. 50:91-99.

Kang, M.S., 1993. Simultaneous selection for yield and stability in crop performance trials: Consequences for growers. Agron. J. 85:754-757. 
Kato, Y., Collard, B.C.Y., Septiningsih, E.M., Ismail, A.M., 2014. Physiological analyses of traits associated with tolerance of long-term partial submergence in rice. AoB-PLANTS 6, plu058, http://dx.doi.org/10.1093/aobpla/plu058.

Kempton, R.A., 1984. The use of biplots in interpreting variety by environment interaction. J Agric Sci, 103:123-135.

Lafitte H.R., Ismail A., Bennet J., 2004. Abiotic stress tolerance in rice for Asia: progress and future. In: Fischer T, Turner N, Angus J, McIntyre L, Robertson M, Borrell A, et al. eds. New Directions for a Diverse Planet: Proceedings for the 4th International Crop Science Congress. The Regional Institute Ltd. Proceedings available online: www.cropscience.org.au/icsc2004

Munns R. and Tester M., 2008. Mechanisms of salinity tolerance. Annu. Rev. Plant Biol. 59:651681

Rad, M.R.N., Kadir M.A., Rafii M.Y., Jafar H.Z.E., Naghavi M.R. and Ahmadi F., 2013. Genotype X environment interaction by AMMI and GGE biplot analysis in three consecutive generations of wheat (Triticum aestivum) under normal and drought stress conditions. AJCS. 7 (7): 956-961.

Salam, M.A., Islam M.R., Rahman M.S., Rahman M.A., Bhuiyan M.A.R., Seraj Z.I., Aditya T.L., Uddin M.K., Mondal M.K., Ismail A.M., Adorada D.L., Mendoza R.D., Tumimbang-Raiz E. and Gregorio G.B., 2010. Rice varieties and cultural management practices for high and sustained productivity in the coastal wetlands of Southern Bangladesh. In: Tropical Deltas and Coastal Zones: Food production, Communities and Environment at the Land-Water Interface. CABI Publisher, Uk. Pp 183-198. 
Shrestha SP, Asch F, Dusserre J, Ramanantsoanirine A, Brueck H, 2012. Climate effects on yield components as affected by genotypic responses to variable environmental conditions in upland rice systems at different altitudes. Field Crops Res, 134:216-228.

Singh, S., Mackill, D.J., Ismail, A.M. 2011. Tolerance of longer-term partial stagnant flooding is independent of the SUB1 locus in rice. Field Crops Res. 121, 311-323.

Tariku, S., Lakew, T., Bitew, M. and Asfaw, M., 2013. Genotype by environment interaction and grain yield stability analysis of rice (Oryza sativa L.) genotypes evaluated in north western Ethiopia. Net Journal of Agricultural Science. 1: 10-16.

Thillainathan, M., Fernandez, G.C.J., 2001. SAS applications for Tai's stability analysis and AMMI model in genotype $\times$ Environmental Interaction (GEI) effects. J Hered, 92(4):367371.

Vergara, G.V., Nugraha, Y., Esguerra, M.Q., Mackill, D.J., Ismail, A.M., 2014. Variation in tolerance of rice to long-term stagnant flooding that submerges most of the shoot will aid in breeding tolerant cultivars. AoB PLANT 6, plu055,http://dx.doi.org/10.1093/aobpla/plu055.

Yan, W., Hunt L.A., Sheng Q. and Szlavnics Z., 2000. Cultivar evaluation and megaenvironment investigation based on the GGE biplot. Crop Sci. 40: 597-605.

Yan, W., 2001. GGE Biplot-A Windows application for graphical analysis of multi-environment trial data and other types of two-way data. Agron. J. 93:1111-1118.

Yan, W. and Kang M.S., 2003. GGE Biplot analysis: a graphical tool for breeders, geneticists, and agronomists. CRC Press, Boca Raton, Florida. 